\title{
Professor Jarosław Sławek elected Secretary of the International Association of Parkinsonism and Related Disorders
}

\author{
Zbigniew K. Wszolek ${ }^{1}$, Łukasz Stolarczyk ${ }^{2}$ \\ ${ }^{1}$ Co-Editor-in-Chief, Department of Neurology, Mayo Clinic Florida, Jacksonville, Florida, United States \\ ${ }^{2}$ Journal Administrator, Via Medica ${ }^{\mathrm{m}}$, Gdansk, Poland
}

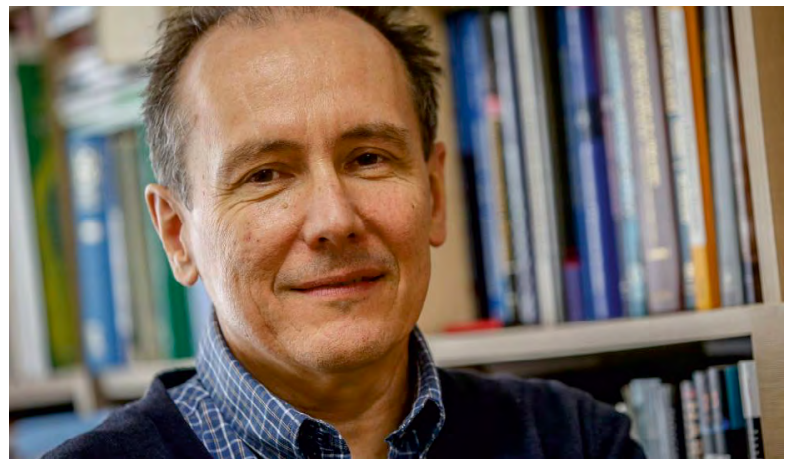

With great pleasure, we announce that Professor Jarosław Sławek, Co-Editor-in-Chief of the Polish Journal of Neurology and Neurosurgery (PJNNS, Neurologia i Neurochirurgia Polska) has just been elected to the position of Secretary of the International Association of Parkinsonism and Related Disorders
(IAPRD). Prof. Sławek holds the positions of Professor of Neurology at the Medical University of Gdansk, Poland and Head of the Neurology \& Stroke Department at the Saint Adalbert Hospital, also in Gdansk. Last month, he completed his fouryear tenure as President of the Polish Neurological Society.

The IAPRD is a professional society of movement disorders specialists from around the world. It was formally incorporated in 2010, but the IAPRD has evolved from the earlier World Federation of Neurology Research Group on Parkinsonism and Related Disorders. IAPRD supports publishing of two subspecialty journals, Parkinsonism \& Related Disorders and Clinical Parkinsonism and Related Disorders. The Association organises biannual international scientific and educational congresses, and holds teaching and educational symposia / meetings in the years in between.

We wish Professor Sławek great success in his new international position. 